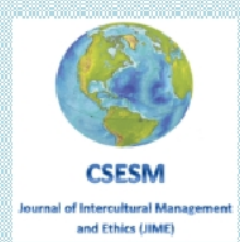

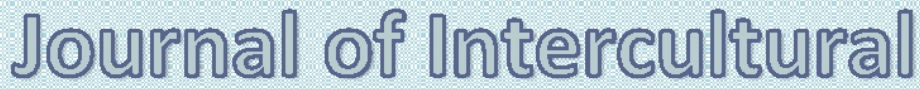

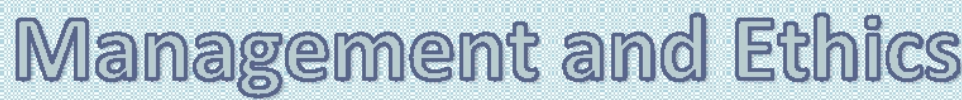

\author{
IOME
}

ISSN 2601 - 5749, ISSN-L 2601 - 5749

\section{published by zy \\ Center for Socio-Economic Studies and Multiculturalism \\ lasi, Romania \\ Waw csesmorg}




\section{Special Editor}

\section{Professor Beatrice Gabriela Ioan, PhD, MD}

Grigore T.Popa University of Medicine and Pharmacy of Iasi, Romania

E-mail: ioanbml@yahoo.com

\section{TABLE OF CONTENT}

Editorial ....

Beatrice Gabriela Ioan

Ethical Approaches on the Mandatory Vaccination in the Pandemic Context (Romania Case)

Andreea-Iulia Someșan, Ion Copoeru

Early Approaches in Management of Sars-Cov-2 Infection 19

Isabela-Ioana Loghin, Adriana-Florina Bahnă, Oana-Manuela Secrieru, Irina-Margareta

Nistor, Irina-Cristina Nicolau, Liviu Jany Prisăcariu, Florin Roșu, Victor Daniel Dorobăţ,

Cristin-Ioan Loghin, Carmen-Mihaela Dorobăț

Giving Birth during the Pandemic. How The Decision to Transform Certain Hospitals In Dedicated Covid-19 Medical Units Impacted Women on Psychological Level

Alexandra Ștefania Nadane

Evangelicalism in Uganda: Implications for Public Health and Bioethics

Sana Loue, Francis Bajunirwe

The Contribution of Ethics to the Development of the Healthcare System

Cornelia Margareta Găşpărel

Iatrogenesis Induced by Risk Reduction in Health Care

Mircea Gelu Buta

Ethical Contributions in Preserving the Dignity of the Terminal Patient

Elena Toader, Andreea Decusara, Mirela Piscuc, Tudor Winsinger

Ethical Aspects of the Institutionalization Process of Children from Outbreaks of

Tuberculosis

Rodica Gramma, Elena Cernăuțeanu, Adriana Paladi

Profession, Vocation, Mission or Work. The Ancient Physician and the Contemporary

Physician-Parallel Lives

Orsolya Horber, K.Zilahi 


\title{
ETHICAL CONTRIBUTIONS IN PRESERVING THE DIGNITY OF THE TERMINAL PATIENT
}

\author{
Elena Toader ${ }^{1,2, *}$, Andreea Decusara ${ }^{2}$, Mirela Piscuc ${ }^{2}$, Tudor Winsinger ${ }^{1}$ \\ ${ }^{1}$ Grigore T. Popa University of Medicine and Pharmacy, Iasi, Romania \\ ${ }^{2}$ Gastroenterology and Hepatology Institute, "St. Spiridon" Clinical County Hospital, Iași, \\ Romania \\ *corresponding author, E-mail: toader.elena@yahoo.com
}

\begin{abstract}
The issue of the terminal patient is an ever-present topic in the approaches focused on the real and efficient control on the end of life, while it entails both in theoretical analysis and practical illustrations a wide category of terms, which have not yet reach consensus despite almost five decades of academic debate. Thus, terms such as assisted dying, end of life, terminal illness, terminal care highlight the manners in which technologic and scientific advances allow for the artificial preservation of vital functions in correlation with a series of medical consequences regarding the increase of life expectancy, effects on health and criteria for establishing the death of an individual. The concerns and deep medical, social, economic and legal implications of the patient diagnosed with a terminal illness define through palliative care the objectives and basic tenets emerging from the ethical aim to preserve the dignity of the patient. Control of symptoms, spiritual state and care for the family of the affected individual are involved in life care or life support therapies and appeal to the principle of beneficence. From the point of view of preserving human dignity, beneficence becomes the basis for the elaboration of bioethical criteria intended for the evaluation of the decisions implicated in the management of the terminally ill patient. Given that, the importance of the dignity of the patient at the end of his or her life cannot be denied, in this paper we aim to identify the ethical attributes which define the concept of dignity, to outline its multidimensional character and the complex nature of this concept.
\end{abstract}

Keywords: dignity, terminal patient, palliative care, ethics, end of life

\section{Introduction}

The attitude towards the finitude of life represented a defining aspect of human existence in all periods, societies and cultures. Death as a universal phenomenon, inherent to the human condition and to other species implies multiple significations. During history, the attitude towards death made the transition from the perception as a public event to a fact of everyday life, which happens inside hospitals, along professionals who are not always prepared to face the matters concerning the end of life (Yanke, 2019). From the gnoseologic point of view, the complexity of the relationship between life and death generated a multidisciplinary approach with the involvement of various domains of human knowledge such as medicine, biology, philosophy, sociology, psychology, theology, etc. Arguments on death and dying individuals accepted in the universal literature, as expressions of the manner of reflecting the moral practices of human kind, were acquired by medical literature in order to ethically ground the concept and the criteria of death, defined on the basis of measurable biomedical standards. The greatest obstacles which professionals in healthcare and patients encounter while trying to understand death are related to a series of difficulties regarding the comprehension of the conventions in the literature, of the concurrencies and cultural 
differences with gaps imposed by time, as well as the lack of emotional depth adequate to this situation (Skelton, 2003). Moreover, persistence in challenging the notions accumulated regarding deep changes brought by the technology of replacing and/or functioning of the organs through transplant or assisted support substantiates the need for ethical debates and argumentation on the line between life and death. Currently, the informing of the patient and his or her close contacts, mainly the family, on the moment when life will be ended, by the importance of the moral dimension, began to require, in the conscience of the actors in the healthcare system justifications for bringing about the ethical contents on the end of life to the central position in case management. Towards this end, in academic debates and practical approaches, the issue of the end of life and the issue of death are outlined within the context of the medical intervention with adequate technologic support, doubled by an ethical support with the positive argumentation of the ethics that applies to the medical act.

\section{Conceptualization and definition of the end of life and of death}

Starting from the consideration that existentially life and death cannot be divided, the definition framework presents death as part of a process which begins concomitantly with entering the terminal stage of a disease or of life. The concepts for the end of life represent a "challenge in recognizing the beginning of this unique period" which, in the opinion of Lamon is focused on two categories of features: medical aspects, based on a perspective concentrating on the disease in the stage of irreversible decline before death and management aspects, as a perspective based on time, correlated with the criteria for admission in the hospital for patients whose life expectancy is limited, generally to a maximum of six months (Lamont, 2005). In the bioethics field, the literature approaches this matter at a reduced scientometric representation concerning the references dedicated to the conceptualization or to the definition of the end of life and of death, both for clinical conditions as well as for the domains dedicated to scientific research. In the theoretical framework we observe trends and approaches of the phenomenon mostly oriented towards the putting into context of the terminology groups unified in common themes rather than towards conceptualization. In clinical approaches, the practicians confronting the matter of the end of life and death are concerned with the exploitation of the manner in which active involvement of ethics may contribute to the elaboration of consensual and standardized definitions (Karnik \& Kanekar, 2016).

\section{The medical component of the end of life and death}

Progress recorded in medicine brought important changes on the manner in which patients experience the existential stage of the end of life. Nevertheless, more support and contributions from research on the final stages of illness and life are necessary. Too little is known on the process of dying, while in the last days of life new symptoms may occur, or the previously controlled symptoms may become exacerbated, or visible again. Current knowledge and understanding is insufficient for the guidance and support of the practice of evidence based medicine for the respect of the preferences of the patients at the end of their lives (Visser et al., 2015). In the absence of definite criteria for the diagnosis of the end of life, constant and precise identification of the stage of death remains a significant incertitude. What happens during the last days, weeks or months of life and which are the physiologic and biologic changes attributed to the process of dying requires further research in order to allow for the acquisition of a knowledge level able to explain the physiologic basis of symptoms. Of a great interest and utility, in a sense exceeding the strictly medical framework is the prognosis assessment for how much life is left after the entrance of the patient in the terminal stage (Bell et al., 2017). In medical practice, recognizing an individual in the last days of his or her life is a complex clinical ability, a challenge for the physician who has to 
distinguish between the irreversible process specific to death and the reversible acute deterioration of the health status. In the absence of a standard definition for the terminal phase, which generally is subjectively assessed by physicians, the moment when a terminally ill patient approaches the end of life remains a continuous challenge for the medical practice confronting difficulties in the recognition of the factors that influence the precision in the prognosis of death in terminal patients (Karnik \& Kanekar, 2016; Hui et al., 2013).

\section{Technologic interventions and contributions in assisting the terminal patient}

The field of medicine recorded significant progress during last decades in the ability to support or replace the function of damaged organs. Embedding the evolutions and discoveries of the 21 st century brought new realities in the medical domain regarding issues and opportunities for caring for the patients at the end of their life. The remarkable implication of biomedical technologies in the improvement of what medicine can do for the prevention and amelioration of the sufferance of those in terminal stages does not exclude a series of limitations generated by the addiction to medical technologies that will increase the impact on the manner in which people choose to die. Following the area of technologic impact in the area of palliative care, Jessica Nutik Zitter and Trial Support signal through statements and results of studies the complex matter of involving high technology medical devices in the care at the end of life, cautioning against the risk of locking the patient in the terminal stage through the usage of intensive care devices (Zitter, 2017; Greipp, 1996). Often pain and significant sufferance of the patient were reported, so the use of the technologic potential for medical purposes may not always correspond to the wishes and expectations of the patients (Karsoho et al., 2016). The ethical justification of reasonably using vital support technologies is involved in the future of technology as well as in the improvement of the decision process at the end of life and in reducing the frequency of patterns of mechanically supported painful death.

\section{Terminal patient - the context of the definition}

The terminal patient is an ever-present subject in the debate dedicated to the real and efficient control on the end of life, modeling the conceptualization of terminology groups on assisted death, end of life, terminal illness, terminal care, transition of care which entered into the focus of the specialists during last five decades ( $\mathrm{Li}$ et al., 2020). The general definition of the death of the human being is equally challenging and difficult in the attempt to unify multiple and diverse modalities of manifestation, often interconnected at the level of the organic life with the mental side and the social component. The terminal patient outlines the manner in which scientific and technologic progress allow for the artificial preservation of vital functions, as well as the medical consequences of these interventions on the increase of life expectancy, effects on health, and the criteria for determining the death of an individual. All these cumulated aspects have a strong impact in the social and economic dimension, with effects and consequences in the medical and law domains. In the medical context of the definition, the terminal patient is that person presenting one of the medical circumstances of a chronic or incurable disease, whose progressive evolution towards advanced stages leads to an increased degree of severity. The orientation towards these approaches is based on cumulated arguments in the domain of the active therapeutic management, whose decreased efficiency or lack of response to treatment substantiates the orientation towards palliative care. From the perspective of prognosis, the terminal patient is viewed as a patient whose life expectancy is less than six months, a period that becomes critical for the patient and his or her family, both from the medical point of view as well as from the psychological and emotional perception. In the bioethical context, the theme of the terminal patient concentrates on the principle of beneficence, as foundation in the elaboration 
of the criteria involved and intended to ethically evaluate the decision to preserve the life of an individual, taking into consideration the ethical implications in the care of terminally ill patients, from the angle of preserving human dignity (Iani et al., 2020; Donato et al., 2016).

\section{What are the issues of a terminal patient care}

From the medical viewpoint, the type of care may be differentiated through formulations such as "assistance for lifecare" or "life supporting therapies", which are in essence common expressions used for any patient in critical condition, requiring assisted care in an ICU. They designated those common therapeutic procedures specific for intensive care, such as mechanical ventilation, renal replacement systems, vasoactive medication, artificial nutrition and blood-derived products, which, in the case of the terminally ill patient interfere with the "common terminal pathways" through which disease and pathological processes may cause death. According to Hastings Center, the therapies for life support comprise interventions for the underlying disease or biological process, administered with the aim to extend life. For Gomez, medical and surgical procedures, as well as emergency interventions are deemed as interventions through which supplementary time is acquired in order to bring the patient to the health condition preceding the disease (Garcia, 2017). For a patient in terminal stage, existentially dominated by sufferance, the common sense of "assistance for life care" or "life supporting therapies" is represented by a new strategy in case management oriented towards palliative care, which, in the ethical utilitarian sense, intends exploration of beneficence at the maximum level of comfort. According to the WHO definition, palliative care is an "approach that improves the quality of life of patients (adults and children) and their families who are facing problems associated with life-threatening illness. It prevents and relieves suffering through the early identification, correct assessment and treatment of pain and other problems, whether physical, psychosocial or spiritual" (WHO, 2018). Key terms of definitions of terminal patient, quality of life, family, life-threatening illness, suffering, early identification, correct assessment, treatment, and pain are also used by the Spanish Society for Palliative Care and included in the definition of palliative care based on "a global, therapeutically active process, which comprises physical, emotional, social and spiritual attention for those suffering from a terminal illness; the main objectives of welfare and promoting dignity and autonomy of the patients and their families, and the therapeutical means, control of symptoms, emotional support and communication when we face an advanced, progressive and incurable disease, without a chance of responding to specific treatment and with foreseeable death in the foreseeable future, caused either by cancer, AIDS or other chronic progressive illnesses" (Ortiz, 2004). These objectives derived from the medical purpose and the basic tenets emerging from the ethical aim of preserving the dignity of the patient such as control of symptoms, spiritual and psychological welfare and the care for the family are actions through which quality of life of the patient is pursued, as long as palliative care does not attempt to cure the patient or to prolong life. In the opinion of Barbero "there is nothing more to be done" is a prohibited expression and an impeachment vote for abandoning the objectives of palliative care for an individual who has no longer a chance to be cured (Benito et al., 2016). Passing to palliative care represents, from a symbolistic perspective the curative attitude as a modality to provide a specific type of care, an expression of the maximum possible welfare in the final stages of the life of a person isolated by the illness, who feels vulnerable and unprotected, alone and facing the silence of the infinity.

\section{Is it possible to preserve the dignity of the patient in terminal stage?}

Although the control of the physical symptoms associated with advanced disease lately recorded significant progress, there were less obvious advances regarding the control of 
the associated emotional state and the approach of the psychosocial and spiritual difficulties of the patients. As the disease progresses and the end is approaching, the emotional sufferance increases, while the perception of the dignity of the patient is damaged. In the case of the patients with incurable diseases, loss of dignity and the close connection with the importance of decision making for specific matters drew the attention on the need to debate this theme in the context of the terminal illnness. The evaluation of the situations that interfere with the dignity of terminal patients showed that the feeling of dignity is preserved only for $54 \%$ of the patients, the remaining percentage reporting occasional and light concerns on dignity (46\%) while for a specific fraction loss of dignity is associated with feeling of degrading and shame (7.5\%) (Donato et al., 2016; Chochinov et al., 2002). In addition, the contributions of family, friends and health professionals to improving the quality of life through well-being and hope have gained an important role in shaping the concept of dignity for cancer patients. Furthermore, the model of dignity became a source of inspiration for therapeutic alternatives materialized in the model of dignity therapy developed by Chochinov for advanced stage cancer patients (Chochinov et al., 2005). In the model of dignity therapy, Chochinov is focusing on the individual and not on the disease. The author attempts through a series of psychotherapeutic interventions to provide a feasible way and a safe manner of identifying the factors correlated with dignity and decreasing the sufferance of the terminal patient. In an approach concentrated on the relationship between the needs of terminal patients and the feeling of damaged dignity, the model follows three categories of aspects: issues correlated with the disease, the repertoire of conserving dignity and the inventory of social dignity. As ethical significance, the model of the dignity therapy is concentrating on the morality of caring for the patient who no longer has the ability to continue to play the role held during his or her life, does not feel any more the satisfaction of emotion annulled by loneliness and does not find sense of the matters. The model of dignity therapy (Sanz Ortiz) - is concerned with the respect for priorities, values and life plan of the patient, celebrating life through benefits provided by palliative care. The morality of palliative care is deontologically supported by arguments according to which medicine must not be viewed as a domain which helps people prevent death, thus placing it outside the obligations of the physician to care and preserve life (Ortiz, 2004; Garcia et al., 2014). The model emphasizes the role of the medical team, with professionals trained in palliative care, who, through their actions with a deep ethical content efficiently respond to the needs of the patient and his or her relatives.

\section{Conclusion}

Preserving human dignity is one of the most significant ethical requirements in medical care, so that respect for the dignity of the patients is highlighted widely in standards for medical assistance and is placed at the center of care. For the professionals in the medical field deeply involved in caring for patients in terminal stages practical approaches from the viewpoint of clinical ethics will facilitate higher exposure to favorable consequences of caring for human dignity and will help the team to decrease the unfavorable consequences resulting from disrespecting dignity in the care for the patient by preventing threatening events. It is necessary for the promotion of the status and importance of the concept of human dignity to incorporate this concept in educational and training programs in the field of medical ethics for healthcare professionals focusing on awareness and assuming the concept of dignity in clinical practice. 


\section{References}

Bell, C., Nielsen, M., K., Neergaard, M., A., et al. (2017). Remaining lifetime after recognition of terminal illness depends on diagnosis: a nationwide population based cohort study. J Pain Symptom Manage, 53, 116-123.

Benito, E., Bofill, C., \& Barbero, J. (2016). Implementing Spiritual Care at the end of life in Spain. European Journal of Palliative Care, 23(2), 98-99.

Chochinov, H., M., Hack, T., Hassard, T., Kristjanson, L., J., McClement, S., \& Harlos, M. (2002). Dignity in the terminally ill: a cross-sectional, cohort study. Lancet, 360(9350), 2026-30.

Chochinov, H., M., Hack, T., Hassard, T., Kristjanson, L., J., McClement, S., \& Harlos, M. (2005). Dignity Therapy: A Novel Psychotherapeutic Intervention for Patients Near the End of Life. J Clin Oncol, 23, 5520-5525.

Donato, S., Matuoka, J., et al. (2016). Effects of dignity therapy on terminally ill patients: a systematic review. Rev Esc Enferm USP, 50(6), 1014-1024.

García L., M., Antonio, J., Barroso, S., \& Coulon, C. M. (2014). Ethical implications of care in terminally ill patients. MEDIC, 22(2), 44-57.

Greipp, M. E. (1996). SUPPORT study results - implications for hospice care. Am J Hospice Palliat Care, 1338-1345.

Hui, D., De La Cruz, M., Mori, M. et al. (2013). Concepts and definitions for "supportive care," "best supportive care," "palliative care," and "hospice care" in the published literature, dictionaries, and textbooks. Support Care Cancer, 21, 659-685.

Iani, L., De Vincenzo, F., Maruelli, A., Chochinov, H., M., Ragghianti, M., Durante, S., \& Lombardo, L. (2020). Dignity Therapy Helps Terminally Ill Patients Maintain a Sense of Peace: Early Results of a Randomized Controlled Trial. Front Psychol., 11, 1468.

Karnik, S., \& Kanekar, A. (2016). Ethical Issues Surrounding End-of-Life Care: A Narrative Review. Healthcare (Basel), 4(2), 24.

Karsoho, H., Fishman, J., Wright, D., \& McDonald, M.E.(2016). Suffering and medicalization at the end of life: the case of physician-assisted dying. Soc Sci Med., 170, 188-196.

Lamont, E. B. (2005). A demographic and prognostic approach to defining the end of life. $J$ Palliat Med., 8(Suppl 1), S12-S21.

Li, Y-C., Feng, Y-H., Hui-Ying Chiang, H-Y., et.al. (2020). The Effectiveness of Dignity Therapy as Applied to End-of-Life Patients with Cancer in Taiwan: A QuasiExperimental Study. Asian Nursing Research, 14, 189e195.

Ortiz, S. (2004). La sedación en el final de la vida. Medicina clínica, 123, 423-5.

Skelton, J. (2003). Death and dying in literature. Advances in Psychiatric Treatment, 9(3), 211-217.

Visser, C., Hadley, G., \& Wee, B. (2015). Reality of evidence-based practice in palliative care. Cancer Biology \& Medicine, 12(3), 193-200.

World Health Organization (2018). Integrating palliative care and symptom relief into primary health care: a WHO guide for planners, implementers and managers. https://www.who.int/publications/i/item/integrating-palliative-care-and-symptomrelief-into-primary-health-care

Yanke, G. (2019). Deconstructing Dignity in Elisabeth Kübler-Ross's On Death and Dying. The American Journal of Bioethics, 19(12), 46-47.

Zitter, J., N. (2017). How The Rise Of Medical Technology Is Worsening Death. https://www.healthaffairs.org/do/10.1377/hblog20171101.612681/full/ 